\title{
Experimental Latin American cinema: History and aesthetics Cynthia Tompkins
}

Austin: University of Texas Press, 2013

El libro de la investigadora argentina Cynthia Tompkins aparece en un momento de renovación de los acercamientos al cine latinoamericano, que se apoya en el redescubrimiento de su historiografía y el rescate de formas cinematográficas que habían sido excluidas del análisis en décadas anteriores, como es el caso del cine silente y la formas documentales. Un giro que encuentra sus bases tanto en la revisión del cine de la década del sesenta - una exploración que no se agota en lo que a perspectivas y nuevos hallazgos se refiere- y en libros como los de Paulo Antonio Paranaguá, que han propuesto severos desafíos para una comprensión comparatista del cine latinoamericano, abriendo aristas y aproximaciones teóricas que rebasen la circunstancia o la descripción nominal o acercamientos que tengan como eje el cine industrial o los cines nacionales.

La palabra "experimental" aparece en el libro de Tompkins para denominar tanto un corpus de filmes del cine latinoamericano contemporáneo, como para definir y profundizar la perspectiva teórica instalada como punto de partida de sus análisis. Su definición proviene de Umberto Eco, quien para Tompkins "propone un contraste entre los elementos típicamente revolucionarios y antagonistas del cine de vanguardia versus la aceptación deseante del experimentalismo, donde la innovación y la crítica ocurre en el marco de una tradición establecida, en el intento de volverse una norma" (2) y se alimenta, en lo esencial, de los planteamientos realizados por Gilles Deleuze en sus estudios sobre cine, particularmente aquellos contenidos en La imagen-tiempo y su noción de "intervalo", comprendido como un desplazamiento de la acción-reacción (Tompkins 1).

Desde aquí, Tompkins propone tanto una contextualización histórica de lo que podríamos llamar una "emergencia experimental" en el cine latinoamericano, cuyas raíces encuentra en la influencia temprana del montaje - es el caso, por ejemplo, de las brasileñas Rien que les heures (Alberto Cavalcanti, 1926), Sao Paulo: sinfonía de una metrópole (Adalberto Kemeny, 1929) o la excepcional Limite (Mario Peixoto, 1931) - y, asimismo, en la entrada del cine documental y la influencia del neorrealismo como estilo: Kukuli (Manuel Chambi y Enrique Figueroa, 1960, Perú) o Tire Dié (Fernando Birri, 1958, Argentina), cuestión que se extiende prácticamente hasta el corpus completo del "nuevo cine latinoamericano" de los años sesenta, que desglosa a nivel nacional. Situando esta inscripción de lo experimental, Tompkins marca un recorrido desde la década del noventa con una reaparición de las técnicas neorrealistas en el llamado "nuevo cine argentino", y establece un corpus de catorce filmes para fijar un recorrido y análisis, entre los que destacan O homem que copiava (Jorge Furtado, 2003 Brasil), Central do Brasil (Walter Salles, 1998, Brasil), Suite Habana (Fernando Peréz, 2003, Cuba), Extranjera 
(Ines de Oliveira Cézar, Argentina, 2007), Batalla en el cielo (Carlos Reygadas, 2005 México) y La hamaca paraguaya (Paz Encina, Cuba, 2008). El análisis de Tompkins se desglosa en distintos capítulos, varios de cuyos planteamientos exceden con creces la cuestión de lo experimental. Es el caso de sus análisis en torno al neo-noir o la road movie, ciñéndose con más precisión en sus análisis sobre el cine de Carlos Reygadas o las mencionadas de Fernando Pérez y Paz Encina, a partir de la noción de una experimentación autoral (sus juegos con la cámara, la postulación de un cine sensorial, el lugar del paisaje) o los juegos con lo documental subvirtiendo el realismo y las convenciones de lo observacional, en el caso de Suite Habana y La hamaca paraguaya.

El corpus seleccionado por Tompkins es una propuesta bien específica pero también curiosa respecto de lo que podríamos llamar lo experimental y nos caben algunas preguntas en torno a ello. Antes que nada, el basar su análisis en Gilles Deleuze y la concepción de una imagen-tiempo, aun cuando expande y enriquece los análisis, pareciera establecer más bien un achatamiento teórico de las recepciones y las posibilidades de asimilar lo experimental en nuestro continente, en términos epistémicos y conceptuales (pensemos en las teorías de lo experimental desde miradas más estructurales o desde la perspectiva del cine expandido). Segundo, el recorrido histórico nos parece correcto pero a la vez impreciso; notable es la ausencia del cine universitario chileno (Cine Experimental Universidad de Chile, fundado por Sergio Bravo) y de nombres fundamentales quizás para pensar lo experimental en nuestro continente, como son el caso de Hugo Santiago, Raúl Ruiz, Claudio Caldini, Nicolás Guillén Landrián, entre otros. Por otro lado, su noción de experimental parece saltarse -así sin más- las exploraciones experimentales de la década del setenta y el ochenta, formuladas desde los escenarios del video y que, en los casos chileno y argentino, ayudaron a desdibujar los límites entre el documental, la ficción y lo experimental, cuestión que ha quedado documentada en la curatoría Visionarios realizada por Arlindo Machado, Jorge La Ferla, Elías Levín, Marta Lucía Pérez (2009-2012). Tercero, creemos que el corpus elegido, si bien es sólido en muchos aspectos, en términos concretos falla en la cita con lo experimental, como en el caso de El aura o los filmes de Carlos Sorín - por mencionar solo dos ejemplos- más cercana al cine industrial en el primer caso y, en el segundo, a un realismo narrativo. En síntesis, creemos que la noción de "experimental" trabajada por Tompkins, por sobreahondar en la crisis des-obrante, o como figura desarticulante y no-clasificatoria (el origen del término, como recuerda Machado, desde la década del sesenta), parece abrirse a una dimensión transversal que cruza cinematografías y estilos que pueden pasar de cierto clasicismo de ficción argumental a la apuesta material y más radical. Quizás lo que nos falta es menos el análisis (siempre de buen nivel, aplicado por Tompkins), que una definición más específica de lo experimental. Una definición que delimite con profundidad un problema, abordando poéticas que ahonden en lo experimental desde una práctica que supere el realismo, el drama o el cine 
industrial, un lugar hacia el cual el libro va llegando, pero que aún nos topa en sus primeras páginas.

Aunque lo que proponemos no es más que una mirada, creemos que el ahondamiento de lo experimental desde las tensiones al interior de agendas discursivas, dentro de campos culturales específicos, puede ayudarnos a comprender mejor fenómenos específicos como el de Caldini o Guillén Landrián. Así, también, nos orienta al reflexionar sobre su exclusión como formato y resabio "no pensado" de un cine que ha apostado por la "gran Historia", dado que es posible que en esa fractura podamos encontrar los índices donde lo experimental actúa como des-obra, des-articulación y disidencia.

Por último, cabe señalar que lo que puede estar en juego es más bien una concepción de lo experimental como espacio de unas prácticas audiovisuales -como han señalado Jorge La Ferla y Eduardo Russo con insistencia- y la necesidad de una apertura en la discusión en ese preciso sentido: ¿cómo, desde una propuesta específica sobre lo experimental como práctica material y discursiva, es posible desmenuzar y pensar la historia del cine latinoamericano? ¿De qué manera esas prácticas experimentales pueden definirse en términos de deslizamiento y contaminación en un "campo ampliado” del cine? ¿De qué manera interrogar esas prácticas para ahondar en su genealogía? Parte de estas interrogantes son las que desafían hoy un campo de estudios y un problema - "lo experimental"- en pleno movimiento: "Inventar un experimental que falta".

\author{
IVÁN PINTO VEAS \\ Universidad de Chile \\ ivanpintoveas@gmail.com
}

REFERENCIAS BIBLIOGRÁFICAS

Deleuze, Gilles. La imagen-tiempo. Barcelona: Paidós, 2000. Impreso.

Paranguá, Paulo Antonio. Tradición y modernidad en el cine de América Latina. México: Fondo de Cultura Económica, 2003. Impreso. 